\title{
A Modified Method to Assess Tidal Recruitment by Electrical Impedance Tomography
}

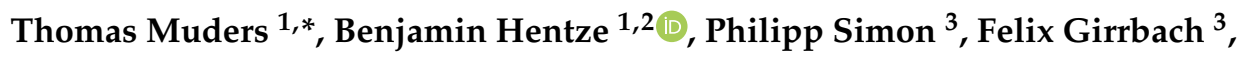 \\ Michael R.G. Doebler ${ }^{1}$, Steffen Leonhardt ${ }^{2} \oplus$, Hermann Wrigge ${ }^{4}$ and Christian Putensen ${ }^{1}$ \\ 1 Department of Anesthesiology and Intensive Care Medicine, University Hospital Bonn, \\ Bonn 53127, Germany \\ 2 Chair for Medical Information Technology, RWTH Aachen University, Aachen 52074, Germany \\ 3 Department of Anesthesiology and Intensive Care Medicine, University of Leipzig, Leipzig 04103, Germany \\ 4 Department of Anesthesiology, Intensive Care and Emergency Medicine, Pain Therapy, \\ Bergmannstrost Hospital Halle, Halle 06112, Germany \\ * Correspondence: t.muders@uni-bonn.de; Tel.: +49-228-287-14119
}

Received: 30 June 2019; Accepted: 1 August 2019; Published: 3 August 2019

check for updates

\begin{abstract}
Avoiding tidal recruitment and collapse during mechanical ventilation should reduce the risk of lung injury. Electrical impedance tomography (EIT) enables detection of tidal recruitment by measuring regional ventilation delay inhomogeneity (RVDI) during a slow inflation breath with a tidal volume $\left(\mathrm{V}_{\mathrm{T}}\right)$ of $12 \mathrm{~mL} / \mathrm{kg}$ body weight $(\mathrm{BW})$. Clinical applicability might be limited by such high $\mathrm{V}_{\mathrm{T}}$ s resulting in high end-inspiratory pressures $\left(\mathrm{P}_{\mathrm{EI}}\right)$ during positive end-expiratory pressure (PEEP) titration. We hypothesized that RVDI can be obtained with acceptable accuracy from reduced slow inflation $V_{T} s$. In seven ventilated pigs with experimental lung injury, tidal recruitment was quantified by computed tomography at PEEP levels changed stepwise between 0 and $25 \mathrm{cmH}_{2} \mathrm{O}$. RVDI was measured by EIT during slow inflation $\mathrm{V}_{\mathrm{T}} \mathrm{S}$ of $12,9,7.5$, and $6 \mathrm{~mL} / \mathrm{kg} \mathrm{BW}$. Linear correlation of tidal recruitment and RVDI was excellent for $\mathrm{V}_{\mathrm{T}} \mathrm{S}$ of $12\left(R^{2}=0.83, p<0.001\right)$ and $9 \mathrm{~mL} / \mathrm{kg}$ BW $\left(R^{2}=0.83, p<0.001\right)$ but decreased for $\mathrm{V}_{\mathrm{T}} \mathrm{S}$ of $7.5\left(R^{2}=0.76, p<0.001\right)$ and $6 \mathrm{~mL} / \mathrm{kg}$ BW $\left(R^{2}=0.71, p<0.001\right)$. With any reduction in slow inflation $\mathrm{V}_{\mathrm{T}}, \mathrm{P}_{\mathrm{EI}}$ decreased at all PEEP levels. Receiver-Operator-Characteristic curve analyses revealed that RVDI-thresholds to predict distinct amounts of tidal recruitment differ when obtained from different slow inflation $\mathrm{V}_{\mathrm{T}} \mathrm{s}$. In conclusion, tidal recruitment can sufficiently be monitored by EIT-based RVDI-calculation with a slow inflation of $9 \mathrm{~mL} / \mathrm{kg}$ BW.
\end{abstract}

Keywords: acute respiratory distress syndrome; positive end-expiratory pressure; electrical impedance tomography; computed tomography; monitoring; functional imaging

\section{Introduction}

In patients with acute respiratory distress syndrome (ARDS), inspiratory overdistension and cyclic opening and collapse of atelectatic but recruitable lung units during tidal ventilation (tidal recruitment) contribute to ventilator-induced lung injury (VILI) [1-4]. The current standard of care for ARDS limiting tidal volumes $\left(\mathrm{V}_{\mathrm{T}}\right)$ and end-inspiratory pressures $\left(\mathrm{P}_{\mathrm{EI}}\right)$ has been shown to reduce VILI and improve mortality in ARDS [5]. Debate exists about the positive end-expiratory pressure (PEEP) level that minimizes tidal recruitment and induces comparatively less VILI [6,7]. Meta-analyses [8,9] did not demonstrate a reduction in mortality using high PEEP strategies in general. This has been partially explained by individual differences in the potential for alveolar recruitment in response to higher PEEP [10]. Clinical studies suggest that in ARDS patients with collapsed but potentially 
recruitable lung tissue, individualized PEEP titration may be beneficial to detect and improve lung recruitment [6] and to minimize tidal recruitment [7].

A conclusion on regional ventilation distribution and regional tidal recruitment [11] cannot be drawn from global indices of lung function. In contrast, electrical impedance tomography (EIT), a non-invasive imaging technique, allows bedside monitoring of regional ventilation [12,13]. We have recently introduced and have validated an EIT-based index; the regional ventilation delay inhomogeneity (RVDI) [14,15] that quantifies temporal heterogeneity in regional ventilation time courses during a slow inflation $\mathrm{V}_{\mathrm{T}}$ maneuver of $12 \mathrm{~mL} / \mathrm{kg}$ body weight (BW). RVDI allows the estimation of PEEP-associated changes of tidal recruitment [15].

When applying our EIT-based method using RVDI to assess tidal recruitment during PEEP-trials in ARDS patients, use of repeated slow inflations $\mathrm{V}_{\mathrm{T}}$ maneuvers of $12 \mathrm{~mL} / \mathrm{kg}$ BW may result in potentially harmful high end-inspiratory overdistension, especially at high PEEP levels, which might limit its clinical applicability. RVDI measurements based on reduced slow inflation $\mathrm{V}_{\mathrm{T}}$ maneuvers are required to decrease $\mathrm{P}_{\mathrm{EI}}$.

We hypothesized that tidal recruitment can also be assessed using RVDI when derived from slow inflation maneuvers with reduced $\mathrm{V}_{\mathrm{T}}$. This hypothesis was investigated by an extended secondary analysis of experimental data derived from a porcine lung injury model.

\section{Animals and Methods}

\subsection{Animals and Ethics}

This study presents an extended analysis of data from a previous investigation in a porcine lung injury model [15]. Experiments were approved by the local ethics committee. Animal housing, care, and experiments were performed in adherence with the Guide for the Care and Use of Laboratory Animals (National Academy of Science 1996). We followed the 3Rs-principle (Appendix A). This study is being reported according to the Animal Research Reporting of In Vivo Experiments (ARRIVE) guidelines (Table S1).

\subsection{Study Protocol}

Anesthesia, Ventilatory Settings, and Induction of Lung Injury

Seven healthy pigs (29-34 kg) were anesthetized, tracheotomized and instrumented in the supine position as previously described [14,15]. Pigs were mechanically ventilated (Engström Carestation, GE Healthcare, Helsinki, Finland) in a volume-controlled mode with a $\mathrm{V}_{\mathrm{T}}$ of $6-8 \mathrm{~mL} / \mathrm{kg} \mathrm{BW}$, a respiratory rate (RR) of $15 \mathrm{~min}^{-1}$, an inspiratory: expiratory ratio of 1:1, a fraction of inspired oxygen $\left(\mathrm{F}_{\mathrm{i}} \mathrm{O}_{2}\right)=0.5$ and a PEEP $=5 \mathrm{cmH}_{2} \mathrm{O}$. Depth of anesthesia was verified by paw pinch before animals were paralyzed, and the absence of spontaneous breathing activity was confirmed by observation of continuously displayed gas-flow tracing [14,15]. Following preparation, lung injury was induced by i.v. injection of oleic acid $(0.1 \mathrm{~mL} / \mathrm{kg})$ in combination with intraabdominal hypertension of $20 \mathrm{cmH}_{2} \mathrm{O}$ caused by intraperitoneal infusion of saline [14,15]. RR was increased up to $30 \mathrm{~min}^{-1}$ to avoid hypercapnia $\left(\mathrm{P}_{\mathrm{a}} \mathrm{CO}_{2}>50 \mathrm{mmHg}\right)$ and $\mathrm{F}_{\mathrm{i}} \mathrm{O}_{2}$ was titrated to maintain a $\mathrm{P}_{\mathrm{a}} \mathrm{O}_{2}$ above $80 \mathrm{mmHg}$. Intrinsic positive end-expiratory pressure was excluded by observation of end-expiratory zero flow patterns at the ventilator. Animals were continuously paralyzed in order to suppress spontaneous breathing efforts.

After lung injury induction and stabilization, animals were transferred to a computed tomography (CT) scanner. PEEP levels of 0, 5, 10, 15, 20 and $25 \mathrm{cmH}_{2} \mathrm{O}$ were applied in a randomized order (sealed envelopes), while all other ventilatory settings remained unchanged. To avoid effects of lung volume history, lungs were derecruited (by disconnection of the respirator) and then recruited by a continuous positive airway pressure of $50 \mathrm{cmH}_{2} \mathrm{O}$ for $40 \mathrm{~s}$ ensuring full lung recruitment [14], before changing PEEP settings, respectively. Any maneuver was preceded by an intravenous fluid bolus of $100 \mathrm{~mL}$ of saline to prevent severe hemodynamic depression, thus maintaining mean arterial blood pressure 
above $55 \mathrm{mmHg}$. After $30 \mathrm{~min}$ of ventilation on the selected PEEP EIT measurements were performed during a single slow inflation maneuver with a constant gas flow by setting the respiratory rate to $4 \mathrm{~min}^{-1}$, which resulted in an inflation time of $7.5 \mathrm{~s}$ and a $V_{T}$ of $12 \mathrm{~mL} / \mathrm{kg}$ BW. Then, spiral-CT scans of the lungs were performed during end-expiration and end-inspiration holds.

\subsection{Measurements and Data Analysis}

Details on cardiovascular, ventilatory, lung mechanics, and blood gas measurements have been reported previously [15].

\subsubsection{Computed Tomography}

Spiral-CT scans $(120 \mathrm{kV}, 120 \mathrm{~mA})$ covering the complete lung tissue were performed during end-expiration and end-inspiration holds using a Brilliance 64 CT scanner (Philips Healthcare, Hamburg, Germany). Tidal volume was $6-8 \mathrm{~mL} / \mathrm{kg}$ BW. Images were reconstructed in slices of $8 \mathrm{~mm}$ using a standard filter. Densitometric analysis of all pulmonary CT slices was performed using a computer program (Osiris, University of Geneva, Switzerland) as described previously [14,15]. The amount of non-aerated lung tissue (defined as densities between -100 and +100 Hounsfield units) was derived from all CT slices. Tidal recruitment was calculated for the total lung as differences between amounts of non-aerated lung tissue at end-in- and end-expiration [14,15].

\subsubsection{Electrical Impedance Tomography}

An EIT system (EIT evaluation KIT II, Dräger Medical GmbH, Lübeck, Germany) was used. Image reconstructions were performed using a modified Newton-Raphson algorithm and images of ventilation distribution were generated by comparing impedance changes to a reference state [15].

\subsubsection{Quantification of Heterogeneity in Ventilatory Time Courses}

Regional and global time courses of impedance changes were recorded with a temporal resolution of $20 \mathrm{~Hz}$ during a single slow inflation maneuver [15]. The global impedance-time curve $\Delta Z(t)$ was calculated as the sum of the impedance changes of all pixels.

Regional-Ventilation-Delay time $\left(\Delta t_{\mathrm{RVD}}\right)$ [15] was determined between the start of inspiration defined as first increase of the global $\Delta Z(t)$ curve and the time when the respective regional curve $\Delta Z_{i}(t)$ reached a threshold of $40 \%$ of the maximal local impedance change (Figure 1). To address the fact that $\Delta t_{\mathrm{RVD}}$ depends on inflation time $\left(\Delta t_{\max }-\min \right), \Delta t_{\mathrm{RVD}}$ was normalized by division through $\Delta t_{\max \text {-min }}$ :

$$
\mathrm{RVD}=\Delta t_{\mathrm{RVD}} / \Delta t_{\max }-\min
$$

The regional-ventilation-delay index (RVD) describes the delay given in (\%) of inflation time until the respective regional impedance change exceeds a certain threshold [15].

RVDs were obtained pixel-to-pixel and a color-coded map was plotted to visualize the pixels' RVDs (Figure 1). To quantify temporal heterogeneity, RVD-inhomogeneity (RVDI) was calculated as the standard deviation of all single-pixel RVDs ( $\mathrm{SD}_{\mathrm{RVD}}$, Figure 1) after filtering and masking [15].

Originally, RVDI was shown to correlate well with tidal recruitment, when calculated from a slow inflation maneuver with a $\mathrm{V}_{\mathrm{T}}$ of $12 \mathrm{~mL} / \mathrm{kg}$ BW [15]. Under the assumption of constant gas flow, the applied volume will increase linearly with time. Thus, in order to obtain slow inflation maneuvers with reduced tidal volumes of $9,7.5$, and $6 \mathrm{~mL} / \mathrm{kg}$ BW it is possible to truncate the full EIT data of $12 \mathrm{~mL} / \mathrm{kg}$ BW after $75 \%, 62.5 \%$, and $50 \%$ of the elapsed time. Our custom MATLAB software is then applied to the truncated EIT data to simulate RVDI analysis at reduced tidal volumes. Details are given in Figure 1.

Accordingly, $\mathrm{P}_{\mathrm{EI}}$ resulting from reduced slow inflation $\mathrm{V}_{\mathrm{T}}$ maneuvers were estimated based on the pressure measurements during the original $12 \mathrm{~mL} / \mathrm{kg}$ BW maneuvers. 
A
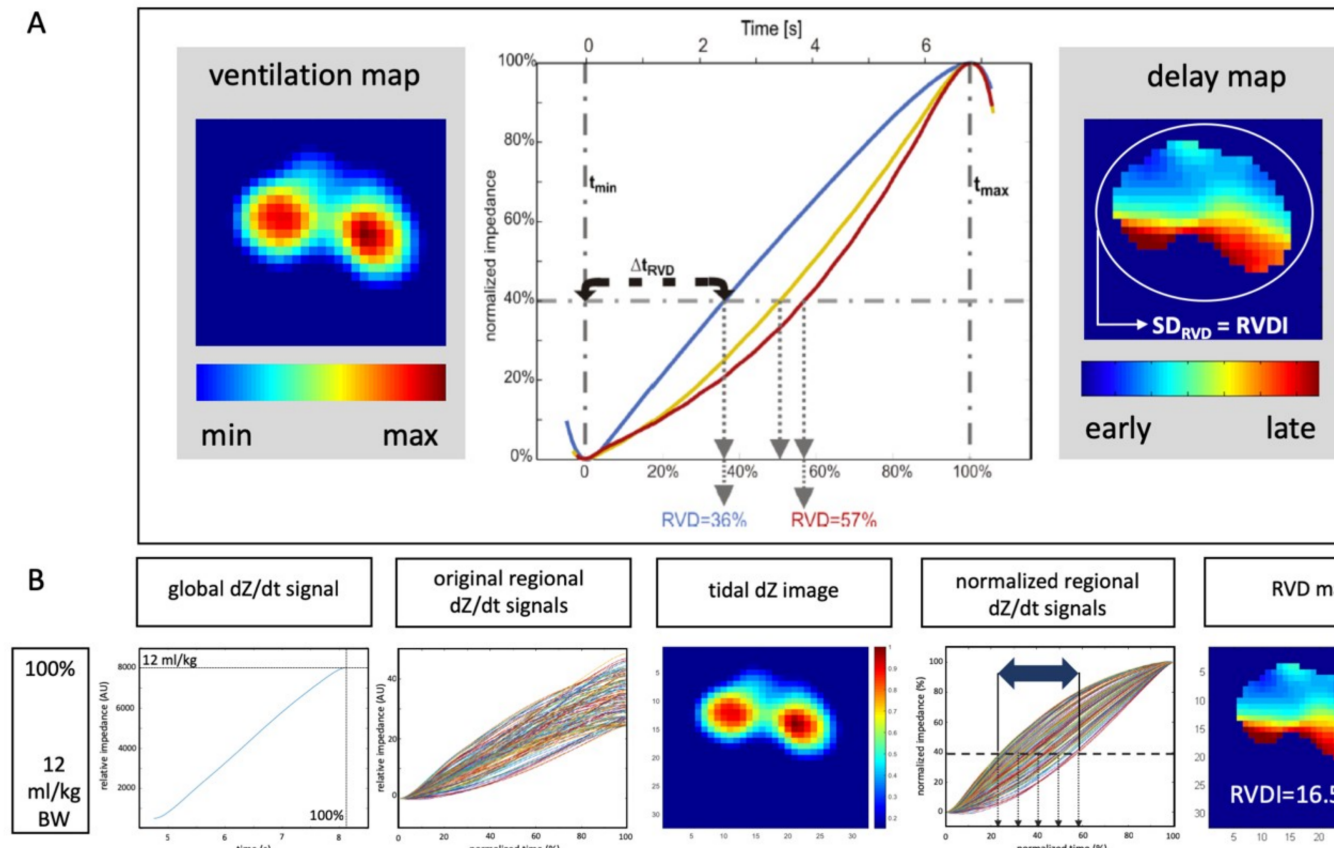

(n)
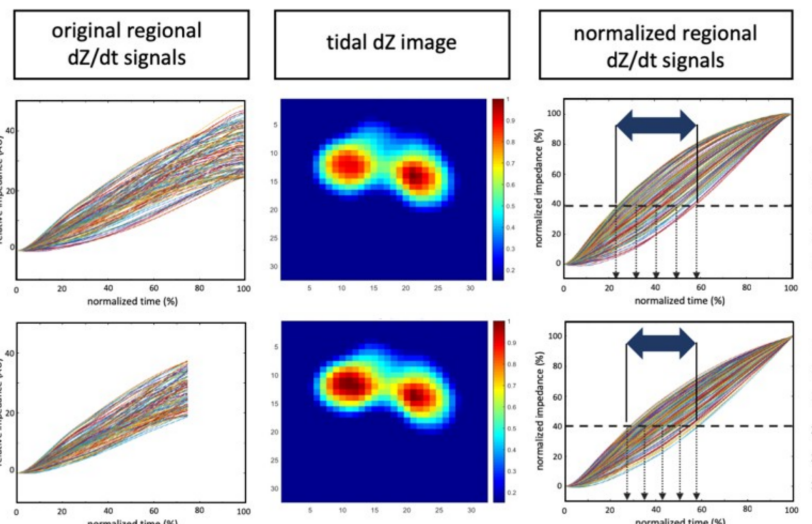

RVD map
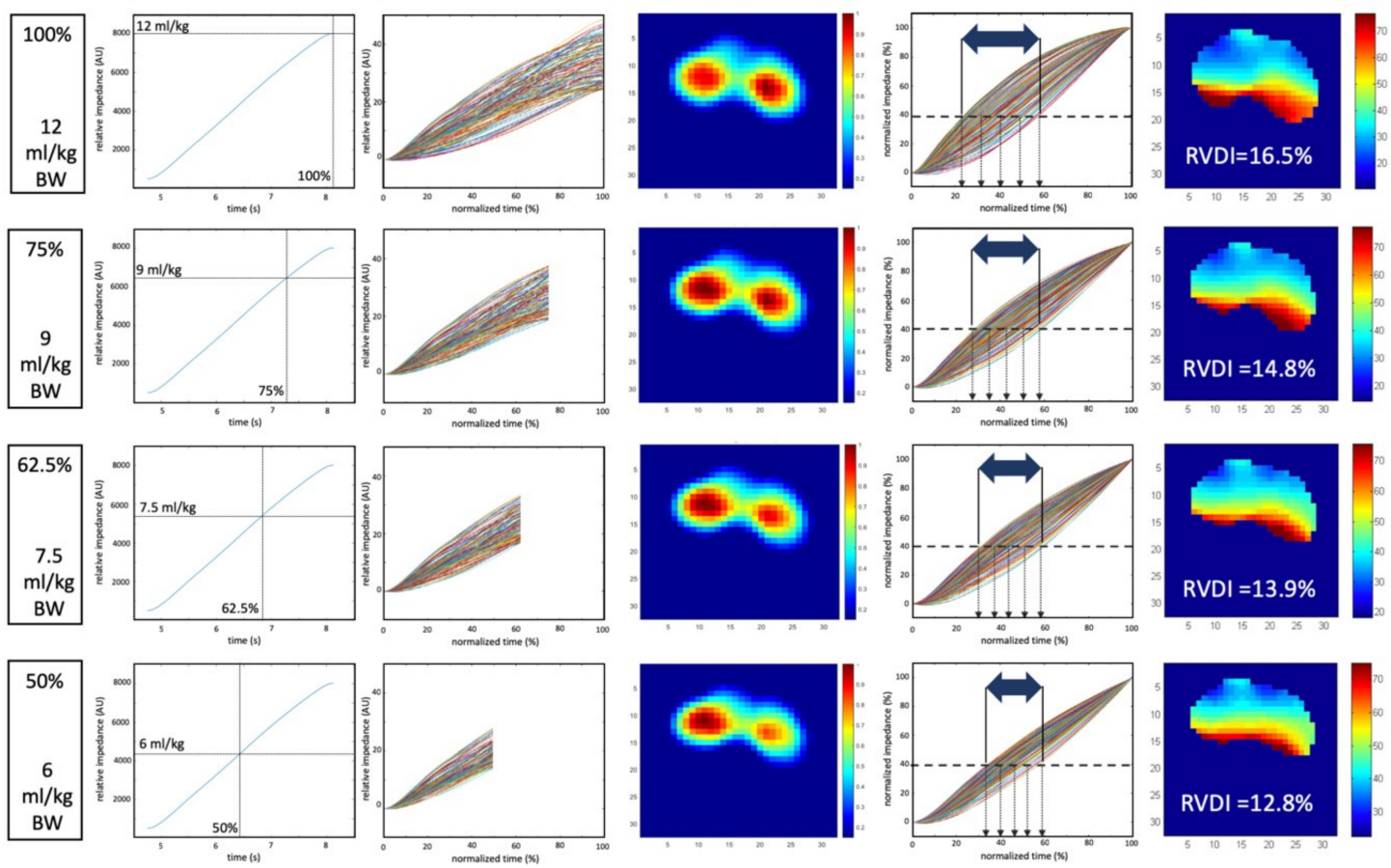

Figure 1. (A) Left ventilation map (tidal dZ image) from a slow inflation; middle: Normalized regional impedance/time curves of three exemplary pixels, blue: Early aerated, yellow: Delayed aeration, red: Very late aeration. Regional-Ventilation-Delay time $\left(\Delta t_{\mathrm{RVD}}\right)$ as the difference between the start of inspiration and the time when the respective regional curve $\Delta Z_{i}(t)$ reaches a threshold of $40 \%$ of the maximal local impedance change. $\mathrm{RVD}=\Delta t_{\mathrm{RVD}} / \Delta t_{\max }-$ min; right: Delay map: Color coding of pixel-wise regional-ventilation-delay (RVD) indices; Regional ventilation delay inhomogeneity (RVDI): Quantification of temporal heterogeneity (regional ventilation delay inhomogeneity). (B) Schematic description; calculation of RVD indices and RVDI from the original $12 \mathrm{~mL} / \mathrm{kg}$ inflation (analyses from $100 \%$ inflation time) and simulation of inflations of reduced inflation volumes of $9,7.5$, and $6 \mathrm{~mL} / \mathrm{kg}$ (analyses from electrical impedance tomography (EIT) signals truncated after $75 \%, 62.5 \%$, and 50\% inflation time). Images show global $\mathrm{dZ} / \mathrm{dt}$ curves, original regional $\mathrm{dZ} / \mathrm{dt}$ curves, tidal $\mathrm{dZ}$ images (ventilation map), normalized regional dZ/dt curves for RVD analyses, RVD maps (scaled in \% inflation time) and resulting RVDI values. 


\subsubsection{Selection of Definite RVDI Thresholds to Predict Tidal Recruitment}

The entire data on tidal recruitment were divided into quartiles. The threshold for tidal recruitment separating the 1 st from the 2 nd through the 4 th quartiles was $2 \%$ of the total lung volume. The threshold for tidal recruitment separating the 1st and 2nd from the 3rd and 4 th quartiles was $4 \%$ of the total lung volume (Figure 2).

Receiver-Operator-Characteristic (ROC) curve analyses were performed to estimate sensitivity and specificity of certain RVDI thresholds to predict an increase in tidal recruitment. For this purpose, all data pairs (tidal recruitment in \% of lung volume and RVDI in \% inflation time) of the CT-validation cohort were grouped in "below" vs. "above" $2 \%$ tidal recruitment (threshold separating the 1st from the 2 nd through the 4th quartiles, see above), and "below" vs. "above" $4 \%$ tidal recruitment (threshold separating the 1st and 2nd from the 3rd and 4th quartiles, see above), respectively. "Below" was classified as a control group for the ROC curve analyses. Assessments were performed for RVDI values obtained from $12,9,7.5$, and $6 \mathrm{~mL} / \mathrm{kg}$ BW inflations, respectively.

RVDI thresholds with a fixed sensitivity of $90 \%$ were derived from ROC curves. Finally, an increase of RVDI above these thresholds, when decreasing PEEP, predicts an increase in tidal recruitment above $2 \%$ and $4 \%$ with a sensitivity of $90 \%$, respectively.

\subsection{Statistical Analysis}

Primary outcome measures were RVDI values calculated from different slow inflation volumes. Since no reliable pilot data or data from publications were available for this exploratory study setting, a sample size calculation was not possible. GraphPad Prism (Version 8; GraphPad Software, San Diego, CA, USA) was used for statistical analyses.

RVDI values obtained from different slow inflation tidal volumes at different PEEP levels were compared, using a two-way repeated-measures analysis of variances (ANOVA) after confirming normal distribution (Shapiro-Wilk's-W-test), linear correlations and Bland and Altman analyses. Changes in $P_{E I}$ resulting from different slow inflation $V_{T}$ maneuvers were compared using a two-way repeated-measures analysis of variances (ANOVA) after confirming normal distribution (Shapiro-Wilk's-W-test) and differences were separated using post hoc tests (Dukey). Tidal recruitment measured by CT was linearly correlated with RVDI. Linear correlations were calculated between these parameters for single animals (intra-individually) and between these parameters for all animals of the respective cohort (inter-individually) taking data points from all PEEP levels.

Receiver-Operator-Characteristic curve analyses were performed to estimate sensitivity and specificity of certain RVDI thresholds to predict an increase in tidal recruitment.

Data are given as mean \pm standard deviation (SD), $p<0.05$ was considered significant.

\section{Results}

\subsection{Lung Injury and Cardiopulmonary Effects of Different PEEP Levels}

The lung injury induction caused in all animals an oxygenation and lung mechanics impairment [15] compatible with the current criteria for moderate human ARDS [16]. Effects of different PEEP-levels on hemodynamic and pulmonary parameters have previously been described in detail [15]. Briefly, increasing PEEP levels cause a decrease in cardiac output, mean arterial blood pressure, intrathoracic blood volume, and stroke volume. All animals were hemodynamically stable during recruitment maneuvers.

\subsection{Temporal Heterogeneity Measured by EIT}

Heterogeneity of regional ventilatory time courses as quantified by RVDI decreased with higher PEEP-levels (Figures 2A and 3) when derived from the original inflation maneuver using a slow inflation $\mathrm{V}_{\mathrm{T}}$ of $12 \mathrm{~mL} / \mathrm{kg}$ BW [15]. Present extended analyses show that this effect could also be observed when RVDI was calculated from reduced slow inflation $V_{T}$ of 6 to $9 \mathrm{~mL} / \mathrm{kg}$ BW (Figures 2A and 3). 
Linear correlation between RVDI values calculated from the original slow inflation $V_{T}$ of $12 \mathrm{~mL} / \mathrm{kg}$ $\mathrm{BW}$ maneuver and reduced slow inflation $\mathrm{V}_{\mathrm{T}} \mathrm{s}$ are given in Figure $2 \mathrm{~B}$ and Table 1 . The correlation was excellent when comparing slow inflation $\mathrm{V}_{\mathrm{T}} \mathrm{s}$ of $12 \mathrm{vs.} 9 \mathrm{~mL} / \mathrm{kg} \mathrm{BW}$ and was reduced but still clinically acceptable with further reduction in slow inflation $\mathrm{V}_{\mathrm{T}}$. Absolute values of RVDI decreased with decreasing slow inflation $\mathrm{V}_{\mathrm{T}}$ (Figure 2A). Bland and Altman analyses (Table 1) revealed that systematical bias increased with further reduction in slow inflation $\mathrm{V}_{\mathrm{T}}$.

A

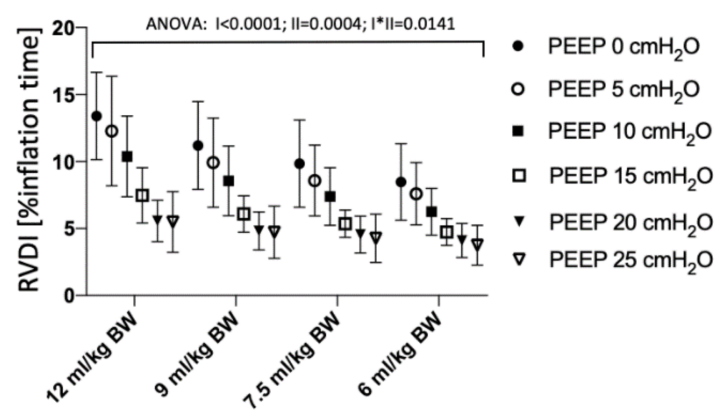

B

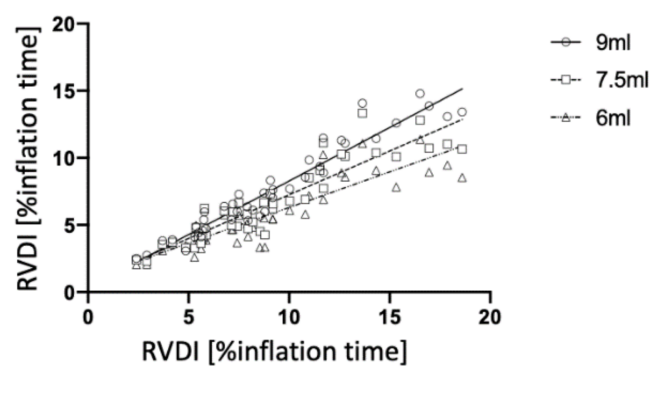

Figure 2. (A) Regional ventilation delay inhomogeneity (RVDI) obtained by electrical impedance tomography (EIT) during a slow inflation with tidal volumes of $12,9,7.5$, and $6 \mathrm{~mL} / \mathrm{kg}$ at positive end-expiratory pressure (PEEP) levels of $0,5,10,15,20$, and $25 \mathrm{cmH}_{2} \mathrm{O}$. Repeated-measures ANOVA: I: factor "PEEP", II: Factor "slow inflation $\mathrm{V}_{\mathrm{T}}$ "; I*II: Interaction of I and II. (B) Linear correlation analysis of RVDI (temporal heterogeneity of regional impedance time curves in \% inflation time) obtained from electrical impedance tomography (EIT) during a slow inflation of $12 \mathrm{~mL} / \mathrm{kg} \mathrm{BW}$ (x-axis) and RVDI calculated from simulated 9, 7.5, and $6 \mathrm{~mL} / \mathrm{kg}$ BW inflations performed at PEEP levels of $0,5,10,15,20$, and $25 \mathrm{cmH}_{2} \mathrm{O}$.

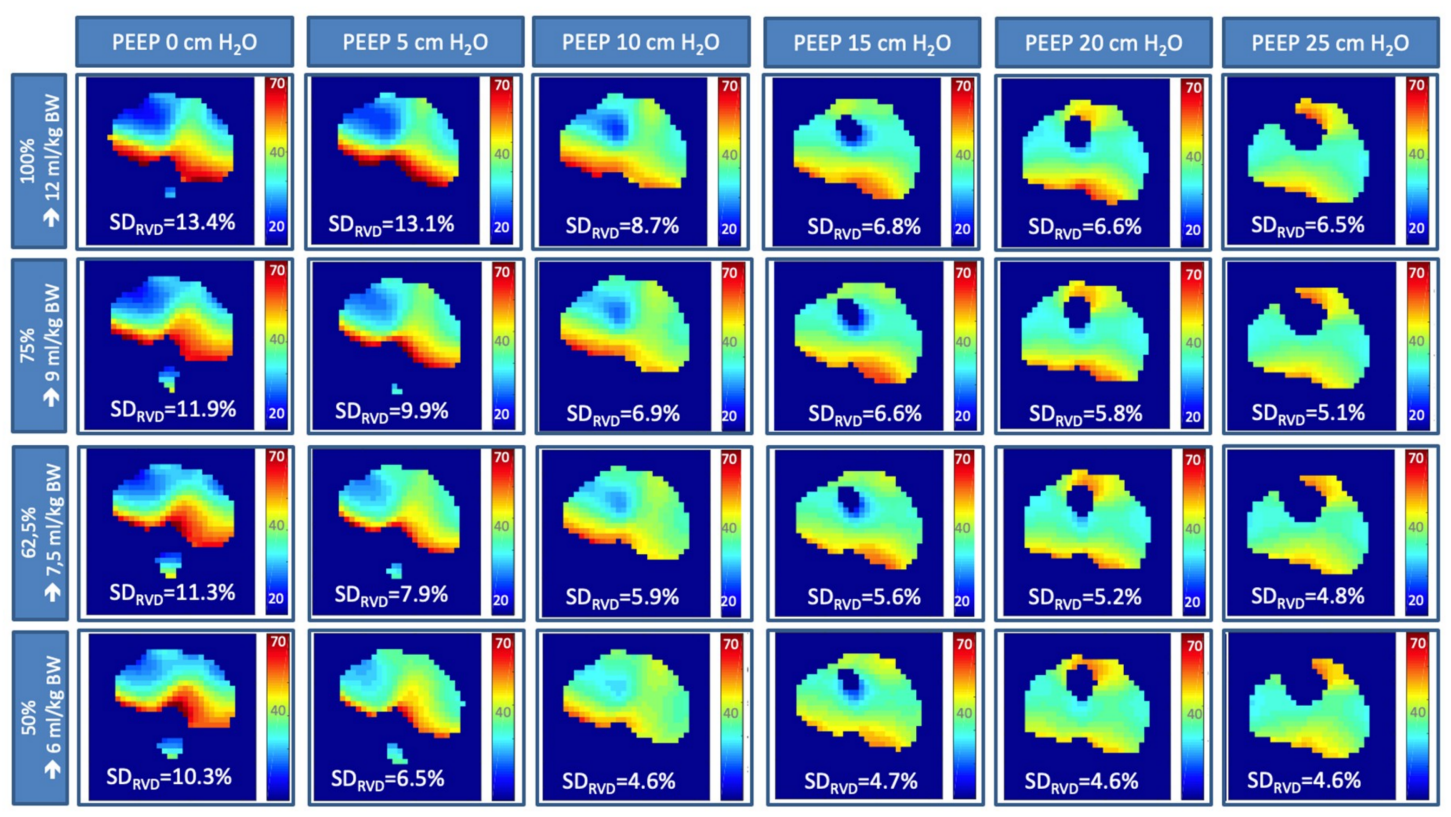

Figure 3. Regional ventilation delay (RVD) analyses, color-coded RVD maps and RVDI values (in \% inflation time) obtained by electrical impedance tomography (EIT) during a slow inflation with tidal volumes of 12, 9, 7.5, and $6 \mathrm{~mL} / \mathrm{kg}$ at PEEP levels of $0,5,10,15,20$, and $25 \mathrm{cmH}_{2} \mathrm{O}$. 
Table 1. Comparison of RVDI values obtained from different slow inflation $\mathrm{V}_{\mathrm{T}}$ maneuvers using Electrical Impedance Tomography.

\begin{tabular}{|c|c|c|c|}
\hline \multirow{2}{*}{ Comparison of RVDI Values } & \multicolumn{3}{|c|}{ Slow Inflation Tidal Volume of $12 \mathrm{~mL} / \mathrm{kg}$ BW vs. } \\
\hline & $9 \mathrm{~mL} / \mathrm{kg} \mathrm{BW}$ & $7.5 \mathrm{~mL} / \mathrm{kg} \mathrm{BW}$ & $6 \mathrm{~mL} / \mathrm{kg} \mathrm{BW}$ \\
\hline \multicolumn{4}{|c|}{ inter-individual comparison, all animals $(n=7)$} \\
\hline linear correlation, $R^{2}, p<0.001$ & 0.93 & 0.84 & 0.76 \\
\hline \multicolumn{4}{|l|}{ Bland Altman analysis } \\
\hline Bias $\pm \mathrm{SD}$ & $-1.5 \pm 1.2$ & $-2.4 \pm 1.9$ & $-3.3 \pm 2.3$ \\
\hline $95 \%$ limits of agreement & -4.0 to 1.0 & -6.1 to 1.2 & -7.8 to 1.2 \\
\hline \multicolumn{4}{|c|}{ intra-individual comparison } \\
\hline \multicolumn{4}{|l|}{ linear correlation, $R^{2}, p<0.001$, respectively } \\
\hline pig 1 & 0.91 & 0.79 & 0.69 \\
\hline pig 2 & 0.9 & 0.8 & 0.73 \\
\hline pig 3 & 0.97 & 0.94 & 0.86 \\
\hline pig 4 & 0.99 & 0.99 & 0.96 \\
\hline pig 5 & 0.99 & 0.99 & 0.97 \\
\hline pig 6 & 0.85 & 0.62 & 0.37 \\
\hline pig 7 & 0.98 & 0.94 & 0.86 \\
\hline
\end{tabular}

Regional ventilation delay inhomogeneity (RVDI) was measured using electrical impedance tomography (EIT) during a slow inflation maneuver to quantify heterogeneity of regional ventilatory time courses.

\subsection{End-Inspiratory Pressures Resulting from Different Slow Inflation $V_{T}$ Maneuvers}

With any reduction in slow inflation $\mathrm{V}_{\mathrm{T}}$, resulting $\mathrm{P}_{\mathrm{EI}}$ significantly decreased at all PEEP levels (Figure 4). Decrease in $P_{E I}$ was more pronounced at lower PEEP levels (Figure 4).

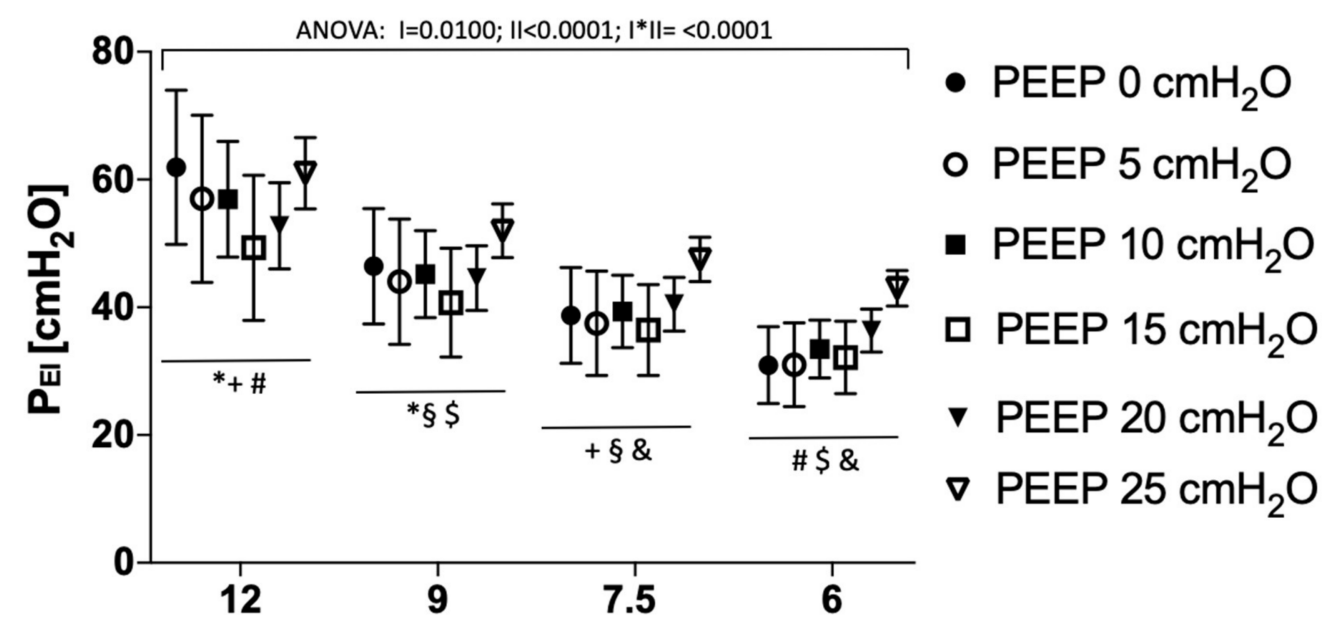

Figure 4. End-inspiratory pressure $\left(\mathrm{P}_{\mathrm{EI}}\right)$ resulting from a slow inflation with tidal volumes of 12, 9, 7.5, and $6 \mathrm{~mL} / \mathrm{kg}$ at PEEP levels of $0,5,10,15,20$, and $25 \mathrm{cmH}_{2} \mathrm{O}$. Repeated measures ANOVA: I: Factor "PEEP", II: Factor "slow inflation $\mathrm{V}_{\mathrm{T}}$ "; I*II: Interaction of I and II; consecutive post hoc tests (Tukey) for differences in $\mathrm{P}_{\mathrm{EI}}$ between different slow inflation tidal volumes at single PEEP levels: * 12 vs.

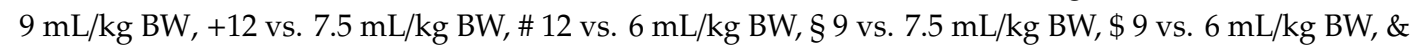
7.5 vs. $6 \mathrm{~mL} / \mathrm{kg} \mathrm{BW}, p<0.001$, respectively.

\subsection{Tidal Recruitment at Different PEEP Levels}

With an increase in PEEP, the amount of tidal recruitment measured by CT decreased [15]. Half of the measurements showed tidal recruitment of more than $4 \%$ of the lung volume (both upper vs. both lower quartiles, Figure 5). For the lowest quartile of the measurements, tidal recruitment was below $2 \%$ of the lung volume (1st vs. 2nd quartile, Figure 5). 
A

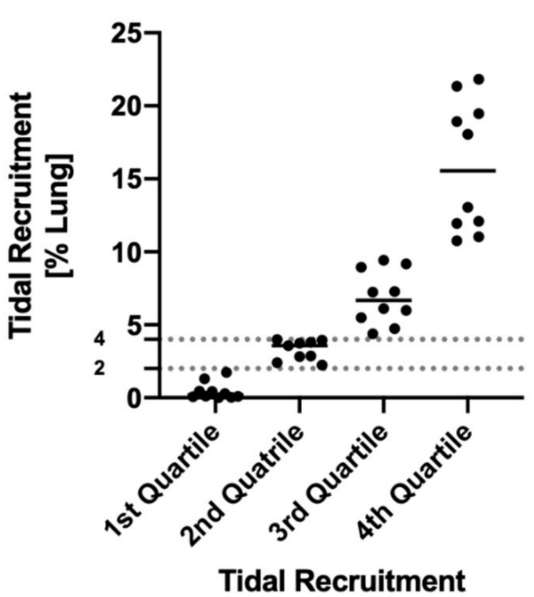

B

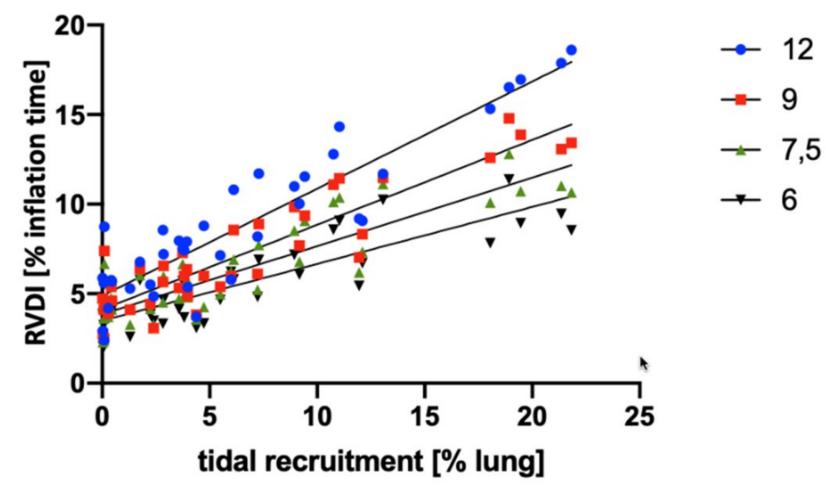

Figure 5. (A) Tidal recruitment obtained from computed tomography at PEEP levels of 0, 5, 10, 15, 20, and $25 \mathrm{cmH}_{2} \mathrm{O}$ in \% of total lung volume; given in four quartiles; a threshold of $2 \%$ separates the 1st from the 2nd through the 4th quartiles; a threshold of $4 \%$ separates the 1 st and 2nd from the 3rd and 4 th quartiles. (B) Linear correlation analysis of tidal recruitment (in \% of total lung volume) vs. RVDI (temporal heterogeneity of regional impedance time curves in \% inflation time) obtained from electrical impedance tomography (EIT) during a slow inflation of $12,9,7.5$, and $6 \mathrm{~mL} / \mathrm{kg}$.

\subsection{Correlation of RVDI and Tidal Recruitment Obtained from Different Slow Inflation $V_{T}$ Maneuvers}

Linear correlation between tidal recruitment (in \% lung volume) quantified by CT and RVDI (in \% inflation time) as measured by EIT during the original $12 \mathrm{~mL} / \mathrm{kg}$ BW slow inflation maneuver was very good to excellent (Figure 5B, Table 2) when calculated inter-individually and intra-individually. Correlations were excellent for RVDI values calculated from a slow inflation $\mathrm{V}_{\mathrm{T}}$ of $9 \mathrm{~mL} / \mathrm{kg}$ but slightly decreased with further reduction in slow inflation $\mathrm{V}_{\mathrm{T}}$ (Figure 5B, Table 2).

Table 2. Linear correlation of tidal recruitment and RVDI values obtained from different slow inflation $\mathrm{V}_{\mathrm{T}}$ maneuvers.

\begin{tabular}{|c|c|c|c|c|}
\hline \multirow[b]{2}{*}{ Comparison of Tidal Recruitment Versus } & \multicolumn{4}{|c|}{ RVDI Values Calculated from a Slow Inflation Tidal Volume o } \\
\hline & $12 \mathrm{~mL} / \mathrm{kg} \mathrm{BW}$ & $9 \mathrm{~mL} / \mathrm{kg} \mathrm{BW}$ & $7.5 \mathrm{~mL} / \mathrm{kg} \mathrm{BW}$ & $6 \mathrm{~mL} / \mathrm{kg} \mathrm{BW}$ \\
\hline \multicolumn{5}{|l|}{ inter-individual comparison, all animals ( $n=7$ ) } \\
\hline linear correlation, $R^{2}, p<0.001$ & 0.83 & 0.83 & 0.76 & 0.71 \\
\hline \multicolumn{5}{|l|}{ intra-individual comparison } \\
\hline \multicolumn{5}{|l|}{ linear correlation, $R^{2}, p<0.001$, respectively } \\
\hline pig 1 & 0.97 & 0.91 & 0.81 & 0.72 \\
\hline pig 2 & 0.91 & 0.95 & 0.95 & 0.94 \\
\hline pig 3 & 0.96 & 0.94 & 0.94 & 0.86 \\
\hline pig 4 & 0.95 & 0.95 & 0.91 & 0.82 \\
\hline pig 5 & 0.83 & 0.77 & 0.75 & 0.74 \\
\hline pig 6 & 0.87 & 0.62 & 0.33 & 0.12 \\
\hline pig 7 & 0.9 & 0.93 & 0.98 & 0.78 \\
\hline
\end{tabular}

Tidal recruitment was derived from spiral computed tomography. Regional ventilation delay inhomogeneity (RVDI) was measured using electrical impedance tomography (EIT) during a slow inflation maneuver to quantify heterogeneity of regional ventilatory time courses.

\subsection{Prediction of Tidal Recruitment thresholds from RVDI Values}

As derived from quartile analyses on tidal recruitment (Figure 5B), a $2 \%$ threshold was chosen to separate the 1st (lowest) from the 2nd through the 4th quartiles of measurements. Accordingly, a $4 \%$ threshold was chosen to separate 1st and 2nd from the 3rd and 4th quartiles. ROC-curve analyses 
were performed to estimate sensitivity and specificity of certain RVDI thresholds to predict an increase in tidal recruitment above the respective threshold ( $2 \%$ or $4 \%$ of the lung volume, respectively) with decreasing PEEP levels (Figure 6). Results of the ROC analyses for the different inflation volumes are given in Table 3. The area under the curve was high for all predicting models. Results were slightly better for the $4 \%$ threshold (Table 3 ). When fixing sensitivity at $90 \%$ specificities (Table 3 ) were higher for the $4 \%$ tidal recruitment threshold.

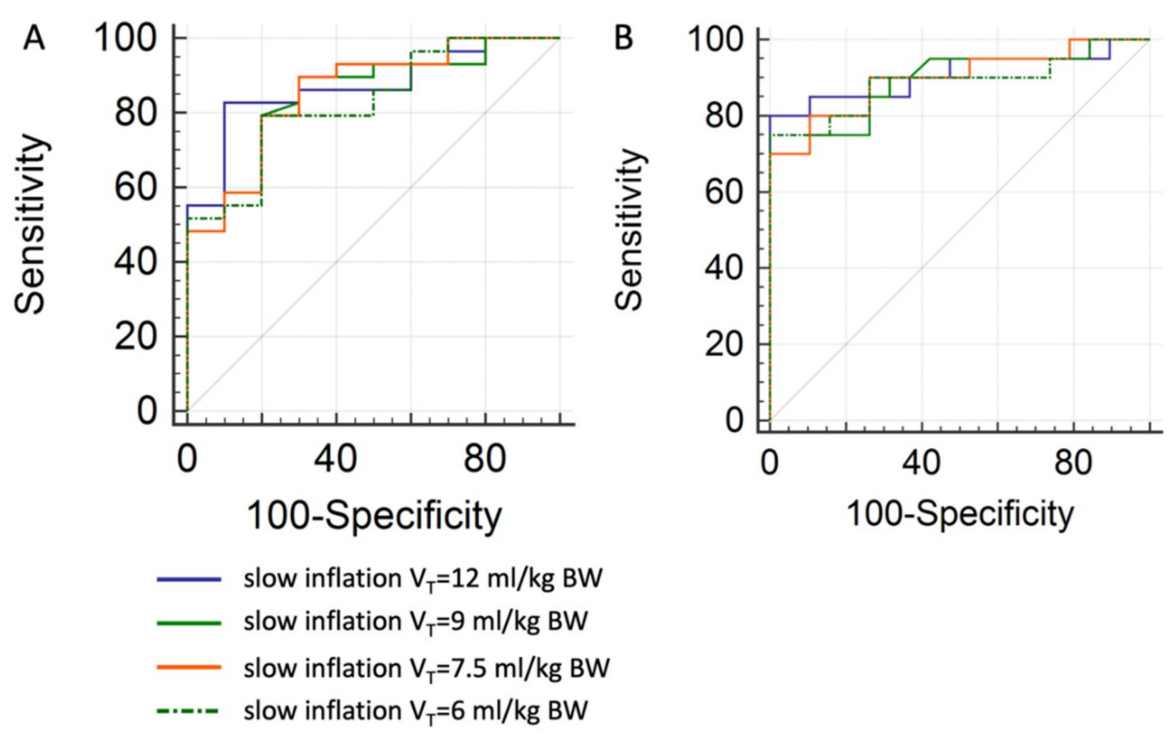

Figure 6. Receiver-Operator-Characteristic (ROC) curve analyses to estimate sensitivity and specificity of certain RVDI values in predicting an increase of tidal recruitment above (A) $2 \%$ or (B) $4 \%$ of the total lung volume with decreasing PEEP. Analyses were performed for RVDI values calculated from slow inflation tidal volumes of 12 (blue), 9 (green), 7.5 (yellow), and 6 (doted) mL/kg. Quantitative analyses are given in Table 3.

Table 3. Receiver-Operator-Characteristic curve analyses to predict tidal recruitment from electrical impedance tomography.

\begin{tabular}{|c|c|c|c|c|}
\hline \multirow{2}{*}{ ROC Curve Analysis } & \multicolumn{4}{|c|}{ RVDI Calculated from a Slow Inflation Tidal Volume of } \\
\hline & $12 \mathrm{~mL} / \mathrm{kg} \mathrm{BW}$ & $9 \mathrm{~mL} / \mathrm{kg} \mathrm{BW}$ & $7.5 \mathrm{~mL} / \mathrm{kg} \mathrm{BW}$ & $6 \mathrm{~mL} / \mathrm{kg} \mathrm{BW}$ \\
\hline \multicolumn{5}{|c|}{ tidal recruitment above $2 \%$ of lung volume } \\
\hline AUC & 0.869 & 0.847 & 0.855 & 0.828 \\
\hline SE & 0.0597 & 0.0688 & 0.0680 & 0.0708 \\
\hline $95 \% \mathrm{CI}$ & 0.722 to 0.955 & 0.695 to 0.942 & 0.706 to 0.947 & 0.673 to 0.929 \\
\hline \multicolumn{5}{|c|}{ tidal recruitment above $4 \%$ of lung volume } \\
\hline AUC & 0.908 & 0.891 & 0.897 & 0.887 \\
\hline SE & 0.0533 & 0.0537 & 0.0521 & 0.0583 \\
\hline $95 \%$ CI & 0.771 to 0.977 & 0.749 to 0.968 & 0.758 to 0.971 & 0.744 to 0.966 \\
\hline
\end{tabular}

RVDI-threshold-based prediction of an increase in tidal recruitment above 2 (\% lung) during decremental

\begin{tabular}{ccccc}
\multicolumn{7}{c}{ PEEP titration } & $>3.34$ \\
RVDI criterion (\% inflation time) & $>5.36$ & $>4.39$ & $>4.15$ & 90 \\
Sensitivity (\%) & 90 & 90 & 90 & 40 \\
Specificity (\%) & 40 & 50 & 60 & $>4.66$ \\
RVDI-threshold-based prediction of an & increase in tidal recruitment above & (\% lung) during decremen \\
\multicolumn{5}{c}{ PEEP titration } \\
RVDI criterion (\% inflation time) & $>6.77$ & $>5.66$ & $>4.88$ & 90 \\
Sensitivity (\%) & 90 & 90 & 90 & 74 \\
Specificity (\%) & 63 & 68 & 74 & \\
\hline
\end{tabular}

Tidal recruitment was derived from spiral computed tomography. Regional ventilation delay inhomogeneity (RVDI) was measured using electrical impedance tomography (EIT) during a slow inflation maneuver to quantify heterogeneity of regional ventilatory time courses. Receiver-Operator-Characteristic (ROC) curve; AUC: area under the curve; SE: standard error; CI confidence interval. 


\section{Discussion}

The main findings of our study in a recruitable porcine lung injury model are:

1. RVDI can be derived from slow inflation maneuvers using a low $\mathrm{V}_{\mathrm{T}}$ of 6 to $9 \mathrm{~mL} / \mathrm{kg} \mathrm{BW}$, to quantify temporal heterogeneity of regional ventilatory time courses.

2. Absolute RVDI values are not comparable when derived from slow inflation maneuvers using different $\mathrm{V}_{\mathrm{T}} \mathrm{s}$.

3. RVDI values from slow inflation maneuvers using low $\mathrm{V}_{\mathrm{T}} \mathrm{s}$ of 6 to $9 \mathrm{~mL} / \mathrm{kg} \mathrm{BW}$ correlate with tidal recruitment.

\subsection{Effects of Slow Inflation $V_{T}$ on RVDI-Values}

Our extended analyses demonstrate that changes in temporal heterogeneity of regional ventilatory time courses can be quantified by RVDI from reduced slow inflation $\mathrm{V}_{\mathrm{T}}$ maneuvers using EIT. RVDI values calculated from reduced slow inflation $V_{T}$ maneuvers correlate well with RVDI values derived from original slow inflation maneuvers using $\mathrm{V}_{\mathrm{T}}$ of $12 \mathrm{~mL} / \mathrm{kg}$ BW. However, slow inflation maneuvers using lower $\mathrm{V}_{\mathrm{T}}$ result in lower RVDI values. This is plausible because RVDI is the variation of regional delay times, which depends on the total duration of the slow inflation $\mathrm{V}_{\mathrm{T}}$. As a consequence, bias increases and agreement between RVDI values decrease when slow inflation $V_{T}$ was reduced to 7.5 $\mathrm{mL} / \mathrm{kg}$ BW or below (Table 1).

As visualized in Figure 1, regional impedance time curves (original regional signal, Figure 1B) show scattered results in the graph. Normalization of impedance changes ( $y$-axis) and inflation times ( $x$-axis, normalized regional signal, Figure 1B) of the regional curves causes a conversion into a spindle-shaped form. The spread of these normalized curves at the $40 \%$ impedance change threshold is quantified by RVDI as visualized by the two-sided arrow in Figure $1 \mathrm{~B}$. Reducing $\mathrm{V}_{\mathrm{T}}$ during slow inflation maneuvers decreased spread of the normalized curves. This suggests that further reduction of $\mathrm{V}_{\mathrm{T}}$ during slow inflation gradually lowers diagnostic resolution and increases the signal-to-noise ratio of the method. We simulatedreduced slow inflation $\mathrm{V}_{\mathrm{T}} \mathrm{s}$ by analyzing the truncated EIT raw data of the original $12 \mathrm{~mL} / \mathrm{kg} \mathrm{BW} \mathrm{V}_{\mathrm{T}}$. This might not further impair our results, since, under the assumption of a constant and slow gas flow, linear reduction of the regional tidal volume should be uniform.

EIT raw data revealed pronounced artefacts in the cardiac region of single animals that interfered with delay measurements during slow inflation maneuvers using a low $\mathrm{V}_{\mathrm{T}}$. This might explain the poor intra-individual correlation of RVDI-values when comparing 12 to $6 \mathrm{~mL} / \mathrm{kg} \mathrm{BW}$ in single animals (Table 1, pig 6, right column).

Finally, absolute RVDI values are not directly comparable, when obtained from different slow inflation $\mathrm{V}_{\mathrm{T}}$ maneuvers. This circumstance prevents comparison of single values of RVDI-measurements derived from different individuals or collectives. Therefore, relative changes in RVDI values might be more significant.

\subsection{Assessment of Tidal Recruitment Using RVDI Measurements}

Linear correlation of RVDI-values and tidal recruitment decreased with a reduction in slow inflation $\mathrm{V}_{\mathrm{T}}$. However, it was still acceptable even when slow inflation $\mathrm{V}_{\mathrm{T}}$ was decreased below $9 \mathrm{~mL} / \mathrm{kg}$ BW. Poor intra-individual correlation of tidal recruitment and RVDI-values derived from $6 \mathrm{~mL} / \mathrm{kg} \mathrm{BW}$ in single animals (Table 2, pig 6, right column) might be explained by cardiac artefacts, as discussed above. Thus, our data suggest that PEEP related changes in tidal recruitment can also be assessed by RVDI-measurements derived from a reduced slow inflation $\mathrm{V}_{\mathrm{T}}$ of $6-9 \mathrm{~mL} / \mathrm{kg}$ BW using EIT.

It is important to note that EIT scans were obtained during slow inflation $\mathrm{V}_{\mathrm{T}}$ maneuvers of 6-12 mL/kg BW, whereas tidal recruitment was measured by CT during subsequent "regular" tidal volume breaths of 6-8 mL/kg BW. As discussed before [15], although obtained during an artificial maneuver with different inflation volume and flow, RVDI-measurements have to be seen as a surrogate 
describing temporal heterogeneity of regional lung mechanics that, in turn, affects tidal recruitment during tidal breaths.

\subsection{PEEP Titration Using EIT}

\subsubsection{EIT-Based Approaches to Individually Titrate PEEP}

Several EIT-based approaches have been conducted to individually optimize ventilatory settings [12,13]. Changes in distribution and homogeneity of end-expiratory lung volume [17] and tidal volume [18-21] were quantified at different airway pressure levels. Zhao et al. [22] demonstrated that the inhomogeneity of spatial ventilation distribution is also influenced by tidal recruitment. Regional lung mechanics were recently derived from EIT to analyze regional collapse [19,23], lung recruitment [24] and overdistension [19,23].

A major advantage of EIT is its high temporal resolution, allowing analysis of aeration and ventilation time courses. Regional filling characters of the lung were initially described in the temporal domain by Hintz et al. [25]. Regional opening pressures have been derived from EIT [26,27]. An "inflation delay" in dependent lung regions during mechanical ventilation has been described by Victorino et al. [28]. Our group introduced and validated the RVD index [14,15] to quantify the temporal heterogeneity of regional ventilation. RVD was also calculated from regular breaths during mechanical ventilation [29], assisted, and spontaneous efforts [30]. However, previous research [15] demonstrated that a slow inflation maneuver is mandatory for sufficient RVDI calculation and assessment of tidal recruitment.

\subsubsection{Regional Ventilation Delay Inhomogeneity to Individually Titrate PEEP}

Various approaches are conceivable to use EIT-based RVDI measurements to individually titrate PEEP in order to reduce tidal recruitment. We used ROC-curve analyses to determine certain RVDI-thresholds to predict an increase in tidal recruitment above $2 \%$ and $4 \%$ of the total lung volume. AUCs were acceptable for all predicting models. When aiming at a fixed sensitivity of $90 \%$, specificity was low $(40 \%-60 \%)$ for the $2 \%$ thresholds but significantly improved (63-74) for thresholds predicting an increase of tidal recruitment above $4 \%$. However, resulting RVDI-thresholds were numerically different when derived from different slow inflation $\mathrm{V}_{\mathrm{T}} \mathrm{s}$. This might limit the clinical applicability of strategies aiming at definite RVDI-thresholds, since separate calibration of RVDI measurements may be necessary for different animal models or groups of patients. However, RVDI-measurements may be used to predicting an increase of tidal recruitment above $4 \%$ although threshold may vary with different slow inflation $\mathrm{V}_{\mathrm{T}} \mathrm{S}$.

Independent of slow inflation $\mathrm{V}_{\mathrm{T}}$ and duration, an increase of temporal heterogeneity in regional ventilatory time courses as indicated by a rise in RVDI indicates an increase in tidal recruitment. Thus, the individual minimum of RVDI might indicate minimal tidal recruitment and allow the selection of the lowest possible PEEP level minimizing tidal recruitment [15]. This promising approach was used by Nestler et al. [31] to individually optimize PEEP during general anesthesia in morbidly obese patients with healthy lungs. Preliminary data of our group [32] show that this strategy might improve regional gas exchange in an animal lung injury model.

\subsection{Clinical Applicability of RVDI Measurements}

As described above an approach minimizing RVDI-values to individually titrate PEEP is, in principle, applicable in humans [31]. However, the safety of the method may be questionable because of the high $\mathrm{V}_{\mathrm{T}} \mathrm{s}$ associated with high end-inspiratory airway pressures.

Without a doubt high $\mathrm{V}_{\mathrm{T}} \mathrm{s}$ during mechanical ventilation are hazardous. In contrast, slow inflation maneuvers are commonly used in respiratory mechanics with even higher inflation volumes and increased airway pressures $[33,34]$. The effects of single slow flow breaths with increased $V_{T} s$ and airway pressures remain unclear and $\mathrm{V}_{\mathrm{T}}$ limits, which are valid for mechanical ventilation cannot be fully 
applied to slow inflation $\mathrm{V}_{\mathrm{T}}$ maneuvers. However, the present study shows that RVDI-measurements obtained from reduced slow inflation $\mathrm{V}_{\mathrm{T}} \mathrm{s}$ of $6-9 \mathrm{~mL} / \mathrm{kg}$ BW may provide valuable information for PEEP titration just as from a $\mathrm{V}_{\mathrm{T}}$ of $12 \mathrm{~mL} / \mathrm{kg}$. Additionally, any reduction in slow inflation $\mathrm{V}_{\mathrm{T}}$ significantly decreased $\mathrm{P}_{\mathrm{EI}}$ at all PEEP levels. With further reduced $\mathrm{V}_{\mathrm{T}}$ and $\mathrm{P}_{\mathrm{EI}}$, the method should be less risky for clinical application.

ARDS is characterized by a broad pathophysiological variability, especially with respect to lung collapse, recruitability, and tidal recruitment. Since our results come from simulated data based on an animal study, findings need to be reproduced in ARDS patients with recruitable and non-recruitable lung collapse while deriving RVDI values from several slow inflation $\mathrm{V}_{\mathrm{T}} \mathrm{s}$. Whether PEEP-titration based on measurements of regional ventilatory heterogeneity is clinically advantageous in ARDS patients warrants further investigations.

\subsection{Limitations}

Our study clearly has several limitations. In our animal model of a highly recruitable lung injury, we combined the widely used oleic acid injection model [35] causing endothelial lung injury [36-38] with increased IAP [39]. Both are commonly seen in extrapulmonary ARDS, e.g., caused by abdominal sepsis [40]. However, results might not be transferable to patients with ARDS without recruitable lung units, e.g., caused by pneumonia. Further research is warranted to evaluate the reproducibility of our findings in humans.

Furthermore, increased abdominal pressure caused relatively high end-inspiratory pressures, due to a reduction in chest wall compliance. Although it is likely that transpulmonary pressures were lower, we cannot prove so, since esophageal pressures were not obtained.

We used recruitment maneuvers with airway pressures up to $50 \mathrm{cmH}_{2} \mathrm{O}$. These pressures were necessary to ensure full lung recruitment in our animal model in order to avoid lung volume history to affect our measurements. However, recruitment maneuvers can be harmful, especially in patients with lower potential for alveolar recruitment. We do not claim these maneuvers as a routine procedure in patients.

For these systematic extended analyses, we simulated reduced slow inflation $\mathrm{V}_{\mathrm{T}}$ maneuvers by "cutting" inflation time of EIT raw data. Assuming constant gas flow during slow inflation reduction of inflation time, slow inflation $\mathrm{V}_{\mathrm{T}}$ will decrease proportionally. Moreover, data simulation enabled an increased utilization of existing experimental animal data according to the 3Rs-principle.

Our RVDI-method has not been validated to detect inspiratory overdistension. We did not find relevant amounts of hyperaerated lung tissue, which might be associated with overdistension, using densitometric CT analysis. As addressed previously, the detection of hyperinflation by quantitative CT in pigs is difficult using a threshold of -900 Hounsfield units. In addition, there might be an interaction between threshold levels for density (Hounsfield unit), slice thickness and reconstruction parameters impairing the detection of hyperinflation [41].

\section{Conclusions}

Temporal heterogeneity of regional ventilatory time courses can be quantified by RVDI using EIT during slow inflation maneuvers with a low $\mathrm{V}_{\mathrm{T}}$, which results in decreased $\mathrm{P}_{\mathrm{EI}}$. This may reduce the risk for clinical application. In our animal model RVDI-measurements from reduced slow inflation $\mathrm{V}_{\mathrm{T}} \mathrm{s}$ are correlated to tidal recruitment. Further research is warranted to reproduce our findings in ARDS patients.

Supplementary Materials: The following material is available online at http://www.mdpi.com/2077-0383/8/8/ 1161/s1, Table S1: ARRIVE checklist.

Author Contributions: Conceptualization, C.P.,H.W. and T.M.; methodology, T.M. and B.H.; software, B.H.; validation, T.M. and B.H.; formal analysis, T.M. and B.H.; investigation, T.M.; resources, C.P., H.W. and S.L.; data curation, T.M. and B.H.; writing—original draft preparation, T.M.; writing-review and editing, T.M., B.H., P.S. 
F.G., S.L.,M.D., H.W., and C.P.; visualization, T.M. and B.H.; supervision, C.P. and H.W.; project administration, C.P.,H.W. and T.M.; funding acquisition, C.P. and H.W.

Funding: This research was funded by grants of the German Research Council (Deutsche Forschungsgemeinschaft, DFG), grant numbers PU 219/2-1and WR47-1-1, and funds of the Department of Anesthesiology and Intensive Care Medicine, University Hospital Bonn, Germany.

Acknowledgments: Draeger Medical provided an EIT device and the ventilator was supplied by GE Healthcare without any restrictions. The University Hospitals of Bonn and Leipzig were supported by research funding from Draeger Medical not related to this study.

Conflicts of Interest: The authors declare no conflict of interest. The funders had no role in the design of the study, the collection, analyses, and interpretation of data; the writing of the manuscript or in the decision to publish the results.

\section{Appendix A}

The original study [15] was approved by the local Animal Research Ethics Committee of the State Office for Nature, Environment and Consumer Protection North-Rhine-Westphalia (LANUV; No. 50.203.2-Bn 43 13/06) and performed in the laboratory of the House of Experimental Therapy (HET), University Hospital Bonn, Bonn, Germany. Animal housing, care, and experiments were performed in adherence with the Guide for the Care and Use of Laboratory Animals (National Academy of Science 1996). The lung injury model allowed rapid changes between states of lung recruitment and enabled repeated measurements at different PEEP levels in a randomized cross-over design to reduce the number of animals (reduction). The pigs were purchased from the local research farm of the University of Bonn, Germany, and were derived from several long-standing colonies (mixed breeds). Animals had free access to food and water until $12 \mathrm{~h}$ before the beginning of experiments. Transportation to the lab was performed immediately before the beginning of experiments. Well established medication schemes [14] were used for analgosedation and euthanasia. We used non-invasive imaging techniques such as EIT and CT for functional lung imaging (refinement). The current study was performed based on data simulation originating from already existing experimental animal data. This enabled a sufficient replacement of additional experiments and increased utilization of the previous study (replacement).

\section{References}

1. This official conference report was cosponsored by the American Thoracic Society the European Society of Intensive Care Medicine and the Societé de Réanimation de Langue Française and approved by the ATS Board of Directors. International Consensus Conferences in Intensive Care Medicine: Ventilator-associated Lung Injury in ARDS. Intensive Care Med. 1999, 25, 1444-1452. [CrossRef]

2. Ranieri, V.M.; Suter, P.M.; Tortorella, C.; De Tullio, R.; Dayer, J.M.; Brienza, A.; Bruno, F.; Slutsky, A.S. Effect of mechanical ventilation on inflammatory mediators in patients with acute respiratory distress syndrome: A randomized controlled trial. JAMA 1999, 282, 54-61. [CrossRef]

3. Slutsky, A.S. Lung Injury Caused by Mechanical Ventilation. Chest 1999, 116, 9S-15S. [CrossRef] [PubMed]

4. Uhlig, S. Ventilation-induced lung injury and mechanotransduction: Stretching it too far? Am. J. Physiol. Cell. Mol. Physiol. 2002, 282, 892-896. [CrossRef] [PubMed]

5. Brower, R.G.; Matthay, M.A.; Morris, A.; Schoenfeld, D.; Thompson, B.T.; Wheeler, A.; Acute Respiratory Distress Syndrome Network. Ventilation with Lower Tidal Volumes as Compared with Traditional Tidal Volumes for Acute Lung Injury and the Acute Respiratory Distress Syndrome. N. Engl. J. Med. 2000, 342, 1301-1308. [PubMed]

6. Gattinoni, L.; Caironi, P.; Cressoni, M.; Chiumello, D.A.; Ranieri, V.M.; Quintel, M.; Russo, S.; Patroniti, N.; Cornejo, R.; Bugedo, G. Lung Recruitment in Patients with the Acute Respiratory Distress Syndrome. N. Engl. J. Med. 2006, 354, 1775-1786. [CrossRef] [PubMed]

7. Caironi, P.; Cressoni, M.; Chiumello, D.A.; Ranieri, M.; Quintel, M.; Russo, S.G.; Cornejo, R.; Bugedo, G.; Carlesso, E.; Russo, R.; et al. Lung Opening and Closing during Ventilation of Acute Respiratory Distress Syndrome. Am. J. Respir. Crit. Care Med. 2010, 181, 578-586. [CrossRef] [PubMed] 
8. Briel, M.; Meade, M.; Mercat, A.; Brower, R.G.; Talmor, D.; Walter, S.D.; Slutsky, A.S.; Pullenayegum, E.; Zhou, Q.; Cook, D.; et al. Higher vs lower positive end-expiratory pressure in patients with acute lung injury and acute respiratory distress syndrome: Systematic review and meta-analysis. JAMA 2010, 303, 865-873. [CrossRef] [PubMed]

9. Putensen, C.; Theuerkauf, N.; Zinserling, J.; Wrigge, H.; Pelosi, P. Meta-analysis: Ventilation strategies and outcomes of the acute respiratory distress syndrome and acute lung injury. Ann. Intern. Med. 2009, 151, 566-576. [CrossRef]

10. Nieman, G.F.; Satalin, J.; Andrews, P.; Aiash, H.; Habashi, N.M.; Gatto, L.A. Personalizing mechanical ventilation according to physiologic parameters to stabilize alveoli and minimize ventilator induced lung injury (VILI). Intensiv. Care Med. Exp. 2017, 5, 1. [CrossRef]

11. Hickling, K.G. The Pressure-Volume Curve Is Greatly Modified by Recruitment: A Mathematical Model of ARDS Lungs. Am. J. Respir. Crit. Care Med. 1998, 158, 194-202. [CrossRef]

12. Muders, T.; Luepschen, H.; Putensen, C. Impedance tomography as a new monitoring technique. Curr. Opin. Crit. Care 2010, 16, 269-275. [CrossRef] [PubMed]

13. Frerichs, I.; Amato, M.B.P.; Van Kaam, A.H.; Tingay, D.G.; Zhao, Z.; Grychtol, B.; Bodenstein, M.; Gagnon, H.; Böhm, S.H.; Teschner, E.; et al. Chest electrical impedance tomography examination, data analysis, terminology, clinical use and recommendations: Consensus statement of the TRanslational EIT developmeNt stuDy group. Thorax 2016, 72, 83-93. [CrossRef] [PubMed]

14. Wrigge, H.; Zinserling, J.; Muders, T.; Varelmann, D.; Günther, U.; Von Der Groeben, C.; Magnusson, A.; Hedenstierna, G.; Putensen, C. Electrical impedance tomography compared with thoracic computed tomography during a slow inflation maneuver in experimental models of lung injury. Crit. Care Med. 2008, 36, 903-909. [CrossRef] [PubMed]

15. Muders, T.; Luepschen, H.; Zinserling, J.; Greschus, S.; Fimmers, R.; Guenther, U.; Buchwald, M.; Grigutsch, D.; Leonhardt, S.; Putensen, C.; et al. Tidal recruitment assessed by electrical impedance tomography and computed tomography in a porcine model of lung injury. Crit. Care Med. 2012, 40, 903-911. [CrossRef] [PubMed]

16. The ARDS Definition Task Force; Ranieri, V.M.; Rubenfeld, G.D.; Thompson, B.T.; Ferguson, N.D.; Caldwell, E.; Fan, E.; Camporota, L.; Slutsky, A.S.; Ranieri, V.; et al. Acute respiratory distress syndrome: The berlin definition. JAMA 2012, 307, 2526-2533.

17. Bikker, I.G.; van Bommel, J.; Miranda, D.R.; Bakker, J.; Gommers, D. End-expiratory lung volume during mechanical ventilation: A comparison with reference values and the effect of positive end-expiratory pressure in intensive care unit patients with different lung conditions. Crit. Care 2008, 12, R145. [CrossRef]

18. Meier, T.; Luepschen, H.; Karsten, J.; Leibecke, T.; Großherr, M.; Gehring, H.; Leonhardt, S.; Grossherr, M. Assessment of regional lung recruitment and derecruitment during a PEEP trial based on electrical impedance tomography. Intensiv. Care Med. 2007, 34, 543-550. [CrossRef]

19. Costa, E.L.V.; Borges, J.B.; Melo, A.; Suarez-Sipmann, F.; Toufen, C.; Bohm, S.H.; Amato, M.B.P. Bedside estimation of recruitable alveolar collapse and hyperdistension by electrical impedance tomography. Intensiv. Care Med. 2009, 35, 1132-1137. [CrossRef]

20. Dargaville, P.A.; Rimensberger, P.C.; Frerichs, I. Regional tidal ventilation and compliance during a stepwise vital capacity manoeuvre. Intensiv. Care Med. 2010, 36, 1953-1961. [CrossRef]

21. Lowhagen, K.; Lundin, S.; Stenqvist, O. Regional intratidal gas distribution in acute lung injury and acute respiratory distress syndrome-Assessed by electric impedance tomography. Minerva. Anestesiol. 2010, 76, 1024-1035. [PubMed]

22. Zhao, Z.; Pulletz, S.; Frerichs, I.; Müller-Lisse, U.; Möller, K. The EIT-based global inhomogeneity index is highly correlated with regional lung opening in patients with acute respiratory distress syndrome. BMC Res. Notes 2014, 7, 82. [CrossRef] [PubMed]

23. Scaramuzzo, G.; Spadaro, S.; Waldmann, A.D.; Böhm, S.H.; Ragazzi, R.; Marangoni, E.; Alvisi, V.; Spinelli, E.; Mauri, T.; Volta, C.A. Heterogeneity of regional inflection points from pressure-volume curves assessed by electrical impedance tomography. Crit. Care 2019, 23, 119. [CrossRef] [PubMed]

24. Spadaro, S.; Mauri, T.; Böhm, S.H.; Scaramuzzo, G.; Turrini, C.; Waldmann, A.D.; Ragazzi, R.; Pesenti, A.; Volta, C.A. Variation of poorly ventilated lung units (silent spaces) measured by electrical impedance tomography to dynamically assess recruitment. Crit. Care 2018, 22, 26. [CrossRef] [PubMed] 
25. Hinz, J.; Gehoff, A.; Moerer, O.; Frerichs, I.; Hahn, G.; Hellige, G.; Quintel, M. Regional filling characteristics of the lungs in mechanically ventilated patients with acute lung injury. Eur. J. Anaesthesiol. 2007, 24, 414-424. [CrossRef] [PubMed]

26. Pulletz, S.; Adler, A.; Kott, M.; Elke, G.; Gawelczyk, B.; Schädler, D.; Zick, G.; Weiler, N.; Frerichs, I. Regional lung opening and closing pressures in patients with acute lung injury. J. Crit. Care 2012, 27, e11-e18. [CrossRef]

27. Becher, T.H.; Bui, S.; Zick, G.; Bläser, D.; Schädler, D.; Weiler, N.; Frerichs, I. Assessment of respiratory system compliance with electrical impedance tomography using a positive end-expiratory pressure wave maneuver during pressure support ventilation: A pilot clinical study. Crit. Care 2014, 18, 679. [CrossRef]

28. Victorino, J.A.; Borges, J.B.; Okamoto, V.N.; Matos, G.F.J.; Tucci, M.R.; Caramez, M.P.R.; Tanaka, H.; Sipmann, F.S.; Santos, D.C.B.; Barbas, C.S.V.; et al. Imbalances in regional lung ventilation: A validation study on electrical impedance tomography. Am. J. Respir. Crit. Care Med. 2004, 169, 791-800. [CrossRef]

29. Blankman, P.; Hasan, D.; Erik, G.J.; Gommers, D. Detection of 'best' positive end-expiratory pressure derived from electrical impedance tomography parameters during a decremental positive end-expiratory pressure trial. Crit. Care 2014, 18, R95. [CrossRef]

30. Bickenbach, J.; Czaplik, M.; Polier, M.; Marx, G.; Marx, N.; Dreher, M. Electrical impedance tomography for predicting failure of spontaneous breathing trials in patients with prolonged weaning. Crit. Care 2017, 21, 177. [CrossRef]

31. Nestler, C.; Simon, P.; Petroff, D.; Hammermüller, S.; Kamrath, D.; Wolf, S.; Dietrich, A.; Camilo, L.M.; Beda, A.; Carvalho, A.R.; et al. Individualized positive end-expiratory pressure in obese patients during general anaesthesia: A randomized controlled clinical trial using electrical impedance tomography. Br. J. Anaesth. 2017, 119, 1194-1205. [CrossRef] [PubMed]

32. Muders, T.; Luepschen, H.; Meier, T.; Leonhardt, S.; Hedenstierna, G.; Putensen, C.; Wrigge, H. Influence of different PEEP setting strategies on regional distribution of pulmonary ventilation, blood flow and strain in porcine lung injury. Int. Care Med. 2010, 36, S206.

33. Gattinoni, L.; Eleonora, C.; Caironi, P. Monitoring of pulmonary mechanics in acute respiratory distress syndrome to titrate therapy. Curr. Opin. Crit. Care 2005, 11, 252-258. [CrossRef] [PubMed]

34. Hata, J.S.; Togashi, K.; Kumar, A.B.; Hodges, L.D.; Kaiser, E.F.; Tessmann, P.B.; Faust, C.A.; Sessler, D.I. The Effect of the Pressure-Volume Curve for Positive End-Expiratory Pressure Titration on Clinical Outcomes in Acute Respiratory Distress Syndrome: A Systematic Review. J. Intensive Care Med. 2014, 29, 348-356. [CrossRef] [PubMed]

35. Matute-Bello, G.; Frevert, C.W.; Martin, T.R. Animal models of acute lung injury. Am. J. Physiol. Lung Cell. Mol. Physiol. 2008, 295, L379-L399. [CrossRef] [PubMed]

36. Gonçalves-De-Albuquerque, C.F.; Silva, A.R.; Burth, P.; Castro-Faria, M.V.; Castro-Faria-Neto, H.C. Acute Respiratory Distress Syndrome: Role of Oleic Acid-Triggered Lung Injury and Inflammation. Mediat. Inflamm. 2015, 2015, 1-9. [CrossRef]

37. Ballard-Croft, C.; Wang, D.; Sumpter, L.R.; Zhou, X.; Zwischenberger, J.B. Large-Animal Models of Acute Respiratory Distress Syndrome. Ann. Thorac. Surg. 2012, 93, 1331-1339. [CrossRef] [PubMed]

38. Wang, H.; Bodenstein, M.; Markstaller, K. Overview of the Pathology of Three Widely Used Animal Models of Acute Lung Injury. Eur. Surg. Res. 2008, 40, 305-316. [CrossRef]

39. Regli, A.; Pelosi, P.; Malbrain, M.L.N.G. Ventilation in patients with intra-abdominal hypertension: What every critical care physician needs to know. Ann. Intensiv. Care 2019, 9, 52. [CrossRef]

40. Gattinoni, L.; Pelosi, P.; Suter, P.M.; Pedoto, A.; Vercesi, P.; Lissoni, A. Acute Respiratory Distress Syndrome Caused by Pulm and extrapulmonary disease. Different syndromes? Am. J. Respir. Crit. Care Med. 1998, 158, 3-11. [CrossRef]

41. Reske, A.W.; Busse, H.; Amato, M.B.P.; Jaekel, M.; Kahn, T.; Schwarzkopf, P.; Schreiter, D.; Gottschaldt, U.; Seiwerts, M. Image reconstruction affects computer tomographic assessment of lung hyperinflation. Intensiv. Care Med. 2008, 34, 2044-2053. [CrossRef] [PubMed]

(C) 2019 by the authors. Licensee MDPI, Basel, Switzerland. This article is an open access article distributed under the terms and conditions of the Creative Commons Attribution (CC BY) license (http://creativecommons.org/licenses/by/4.0/). 